Supporting Information for:

\title{
An Acrylic Platform from Renewable Resources via a Paradigm Shift in Lactide Polymerization
}

\author{
Timothy C. Mauldin, Jason T. Wertz and Dylan J. Boday* \\ IBM Corporation, Materials Engineering, Tucson, AZ 85741, USA \\ Corresponding Author’s Email Address: *dboday@us.ibm.com
}

Table of Contents

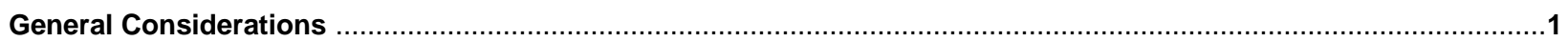

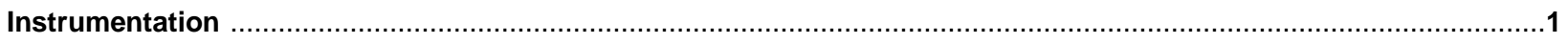

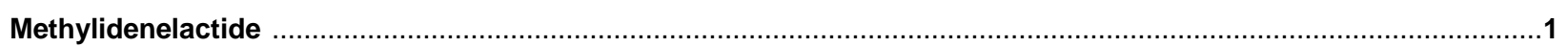

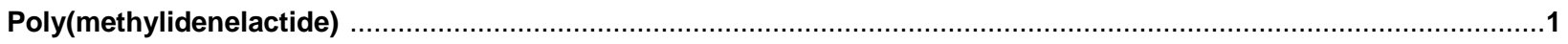

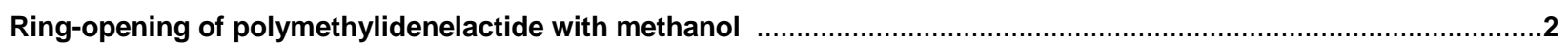

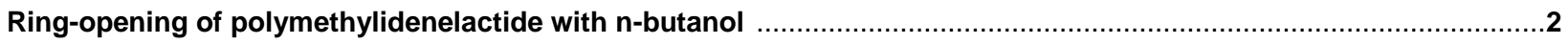

Ring-opening of polymethylidenelactide with benzyl alcohol .......................................................................

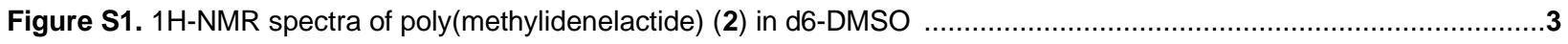

Figure S2. Second heating curve DSC thermogram of poly(methylidenelactide) (2) ..................................................4

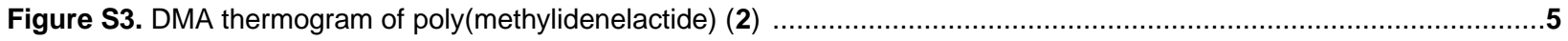

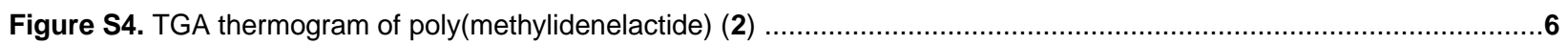

Figure S5. SAXS diffraction pattern of poly(methylidenelactide) (2) ......................................................................

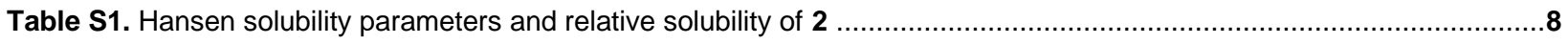

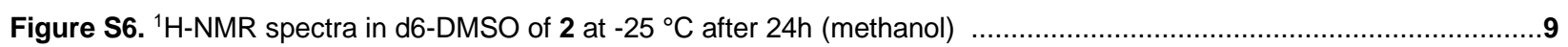

Figure S7. ${ }^{1} \mathrm{H}-\mathrm{NMR}$ spectra in $\mathrm{d} 6$-DMSO of 2 at $5^{\circ} \mathrm{C}$ after $24 \mathrm{~h}$ (methanol) ........................................................10

Figure S8. ${ }^{1} \mathrm{H}-\mathrm{NMR}$ spectra in d6-DMSO of 2 at $23^{\circ} \mathrm{C}$ after $24 \mathrm{~h}$ (methanol) ..............................................................11

Figure S9. ${ }^{1} \mathrm{H}-\mathrm{NMR}$ spectra in $\mathrm{d} 6$-DMSO of 2 at $60{ }^{\circ} \mathrm{C}$ after $24 \mathrm{~h}$ (methanol) ......................................................12

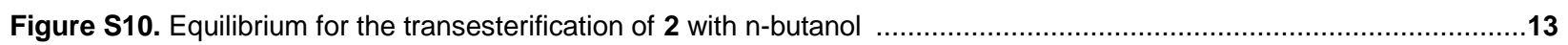

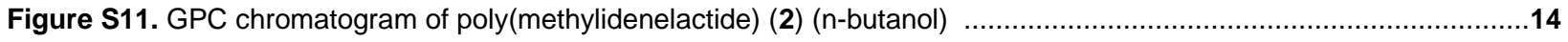

Figure S12. ${ }^{1} \mathrm{H}-\mathrm{NMR}$ spectra in d6-DMSO of 2 at $60^{\circ} \mathrm{C}$ after $24 \mathrm{~h}$ (n-butanol) ........................................................15

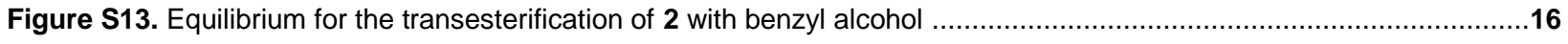

Figure S14. GPC chromatogram of poly(methylidenelactide) (2) (benzyl alcohol) ..................................................17

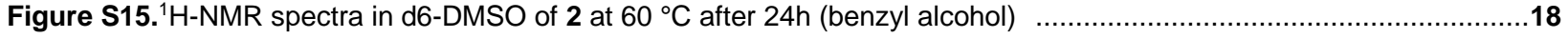


General considerations. L-lactide was received as a gift from Purac and all other chemicals were purchased from Aldrich. N-bromosuccinimide was recrystallized from boiling water immediately prior to use. 2,2'-Azobisisobutyronitrile (AIBN) was recrystallized from cold methanol and stored at $5{ }^{\circ} \mathrm{C}$. Tetrahydrofuran was purchased as anhydrous grade, and inhibitor was removed by running through a plug of basic alumina only when being used as a solvent for radical polymerization. Methanol, n-butanol and benzyl alcohol were purchased in anhydrous grades and stored over $4 \AA$ molecular sieves. 1,5,7-Triazabicyclo[4.4.0]dec-5-ene (TBD) was dried under vacuum prior to use. All other chemicals were used asreceived.

Instrumentation. ${ }^{1} \mathrm{H}$ NMR nuclear magnetic resonance (NMR) spectra were collected on a $400 \mathrm{MHz}$ Bruker AVIII spectrometer. Spectra were collected in d6-DMSO and referenced to added TMS. Structural identification between equilibrium products (i.e., I, II, III and IV) were assigned via differing - $\mathrm{CH} 3$ methyl groups. Gel permeation chromatography (GPC) was done on an Acquity APC system (Waters) with three $4.6 \mathrm{~mm} \times 150 \mathrm{~mm}$ Acquity APC XT columns (450 Å, 2.5 $\mu \mathrm{m} ; 125 \AA$, $2.5 \mu \mathrm{m}$; and $45 \AA, 1.7 \mu \mathrm{m}$ ) connected in series and a refractive index detector calibrated with polystyrene standards. Analysis was performed with THF eluent at $40{ }^{\circ} \mathrm{C}$ with a flow rate of either $0.75 \mathrm{ml} / \mathrm{min}$ or $1 \mathrm{ml} / \mathrm{min}$, and each flow rate was calibrated independently. Differential scanning calorimetry (DSC) was conducted with a Q100 DSC (TA Instruments) via heat-cool-heat cycles at a heating rate of $15 \mathrm{~K} / \mathrm{min}$ and a cooling rate of $10 \mathrm{~K} / \mathrm{min}$. Data from the second heating cycle is reported. Thermogravimetric analysis (TGA) was collected on a Q50 TGA (TA Instruments), and tests were performed under nitrogen gas at a heating rate of $20 \mathrm{~K} / \mathrm{min}$. Dynamic mechanical analysis was done on powder samples in materials pockets (Perkin Elmer N5330323) with a DMA 8000 (Perkin Elmer) using a single-cantilever beam configuration. Samples were heated from $0-275^{\circ} \mathrm{C}$ at $2 \mathrm{~K} / \mathrm{min}$ with a frequency of $1 \mathrm{~Hz}$ and an elongation of $0.05 \mathrm{~mm}$.

Methylidenelactide (1).Bromination of lactide was done according to literature procedure. ${ }^{1}$ Synthesis of methylidenelactide by the same reference was initially difficult to reproduce in reasonable yields and hence was modified as follows: Brominated lactide $(20.0 \mathrm{~g}, 90 \mathrm{mmol})$ was dissolved in in $75 \mathrm{ml}$ tetrahydrofuran under a dry Argon atmosphere and cooled to $0^{\circ} \mathrm{C}$ throughout the course of the reaction. This solution was stirred for 2 hours while triethylamine $(12.5 \mathrm{ml}, 90$ $\mathrm{mmol})$ in $25 \mathrm{ml}$ of tetrahydrofuran was added dropwise slowly $(<1 \mathrm{ml} /$ minute). The solution was immediately filtered and solvent removed under vacuum to reveal an off-white solid. This solid was purified further by recrystallization from dichloromethane to yield white, flaky crystals. The mother liquor was evaporated, and the resulting solid was again recrystallized from dichloromethane. The two batches were combined to reveal $10.8 \mathrm{~g}$ product ( $85 \%$ yield).

Poly(methylidenelactide) (2).Methylidenelactide $(2.0 \mathrm{~g}, 14 \mathrm{mmol})$ and AIBN (24 mg, $0.15 \mathrm{mmol})$ were dissolved in $20 \mathrm{ml}$ tetrahydrofuran under a dry Argon atmosphere in a pressure flask with a Teflon screw top and stirred at $60{ }^{\circ} \mathrm{C}$ for 30 hours. The solution was cooled to room temperature and precipitated into a 20X excess volume of chloroform. The solid 
product was filtered, redissolved in $\sim 20 \mathrm{ml}$ hot tetrahydrofuran over the course of several hours, and precipitated again in a 20X excess volume of hexanes. The resulting solid was dried in a vacuum oven at $85^{\circ} \mathrm{C}$ until complete removal of volatiles (determined by thermogravimetric analysis).

Ring-opening of polymethylidenelactide with methanol. In a typical procedure, poly(methylidenelactide) $(0.2 \mathrm{~g})$ was dissolved in $27 \mathrm{ml}$ of a hot 1:1 (v:v) solution of tetrahydrofuran:methanol (300 molar equivalents of methanol to diester). The flask was sealed under a dry, Argon atmosphere, brought to the desired temperature, and TBD (2 mg, $0.014 \mathrm{mmol})$ dissolved in a minimal amount of methanol was added by syringe. After 24 hours, a 10X excess (relative to TBD) of benzoic acid dissolved in a minimal amount of methanol was added in order to quench the initiator, and the solution was brought to room temperature. The solution was directly added to hexanes dropwise to precipitate the polymer, which was collected by filtration and dried in a vacuum oven at $60^{\circ} \mathrm{C}$ until complete removal of volatiles (determined by thermogravimetric analysis). This procedure was run separately at $-25,5,23$, and $60^{\circ} \mathrm{C}$.

Ring-opening of polymethylidenelactide with $n$-butanol. The procedure above was repeated with a 4:1 (v:v) solution of tetrahydrofuran:n-butanol (300 molar equivalents of n-butanol to diester).

Ring-opening of polymethylidenelactide with benzyl alcohol. The procedure above was repeated with neat benzyl alcohol (300 molar equivalents of benzyl alcohol relative to diester). 


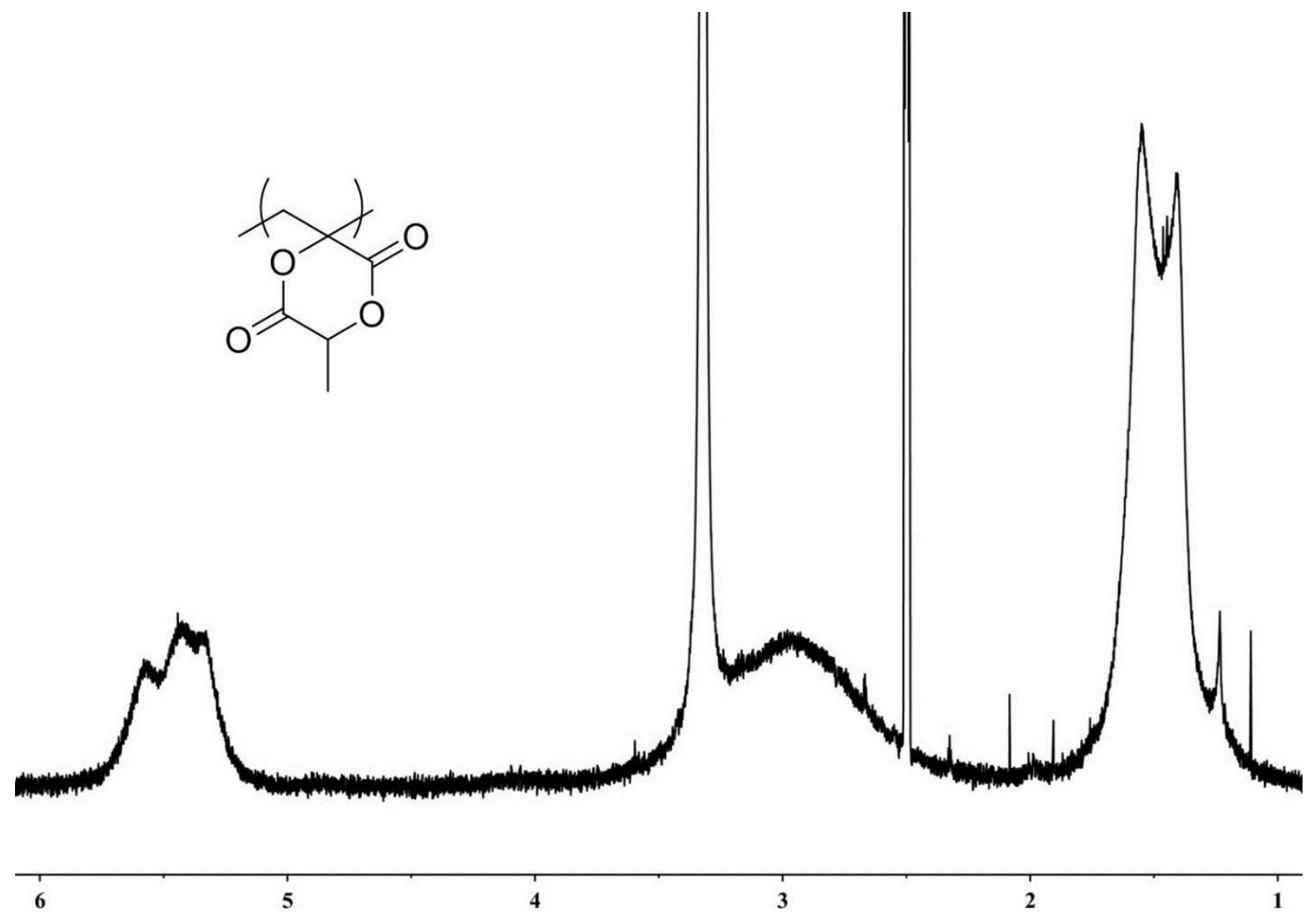

Figure S1. 1H-NMR spectra of poly(methylidenelactide) (2) in d6-DMSO. 


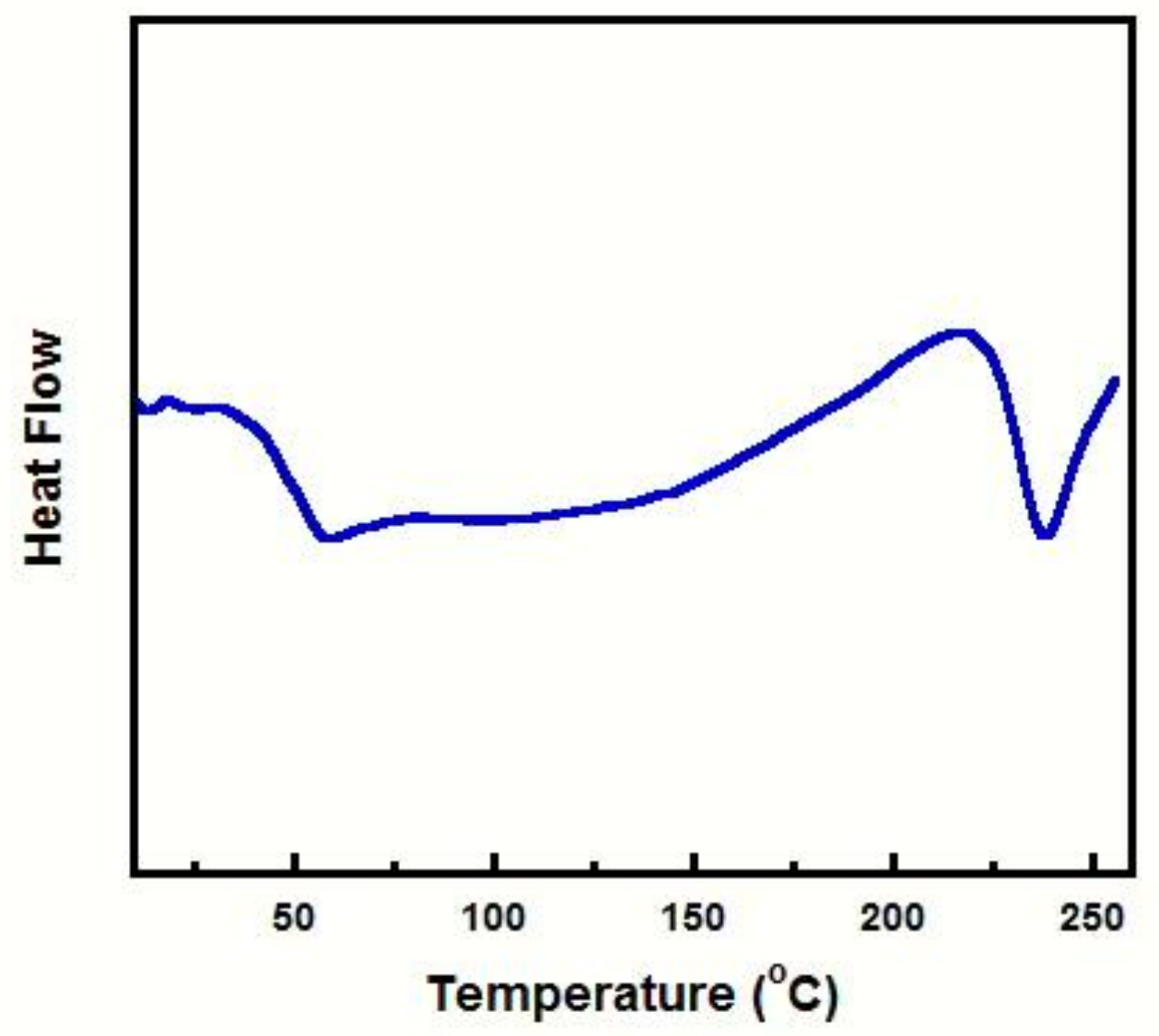

Figure S2. Second heating curve DSC thermogram of poly(methylidenelactide) (2), revealing a beta-transition at $45^{\circ} \mathrm{C}$ and a glass transition at $246^{\circ} \mathrm{C}$ (assignment of $T_{\beta}$ and $T_{g}$ confirmed by dynamic mechanical analysis, vide infra). 


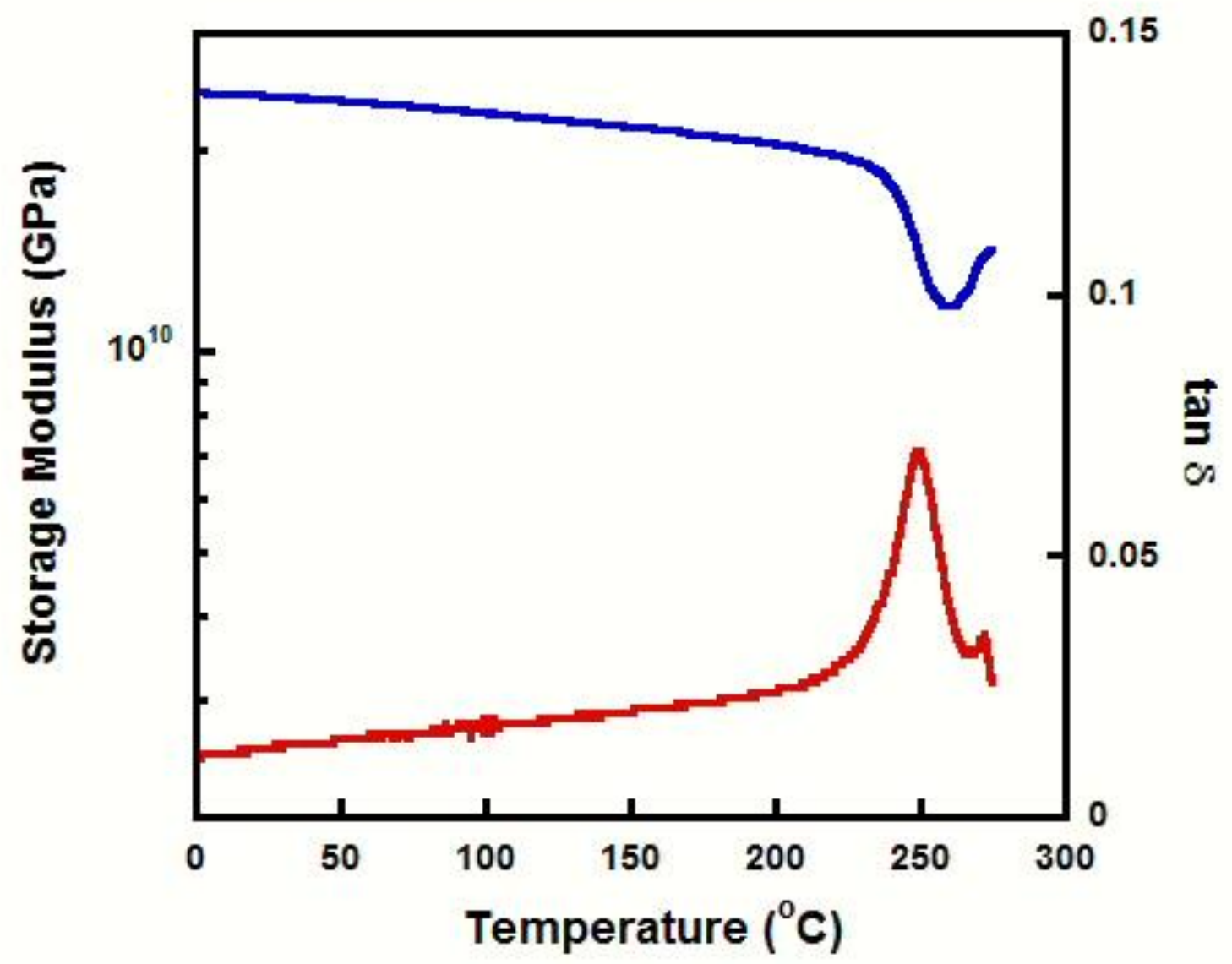

Figure S3. DMA thermogram of poly(methylidenelactide) (2). 


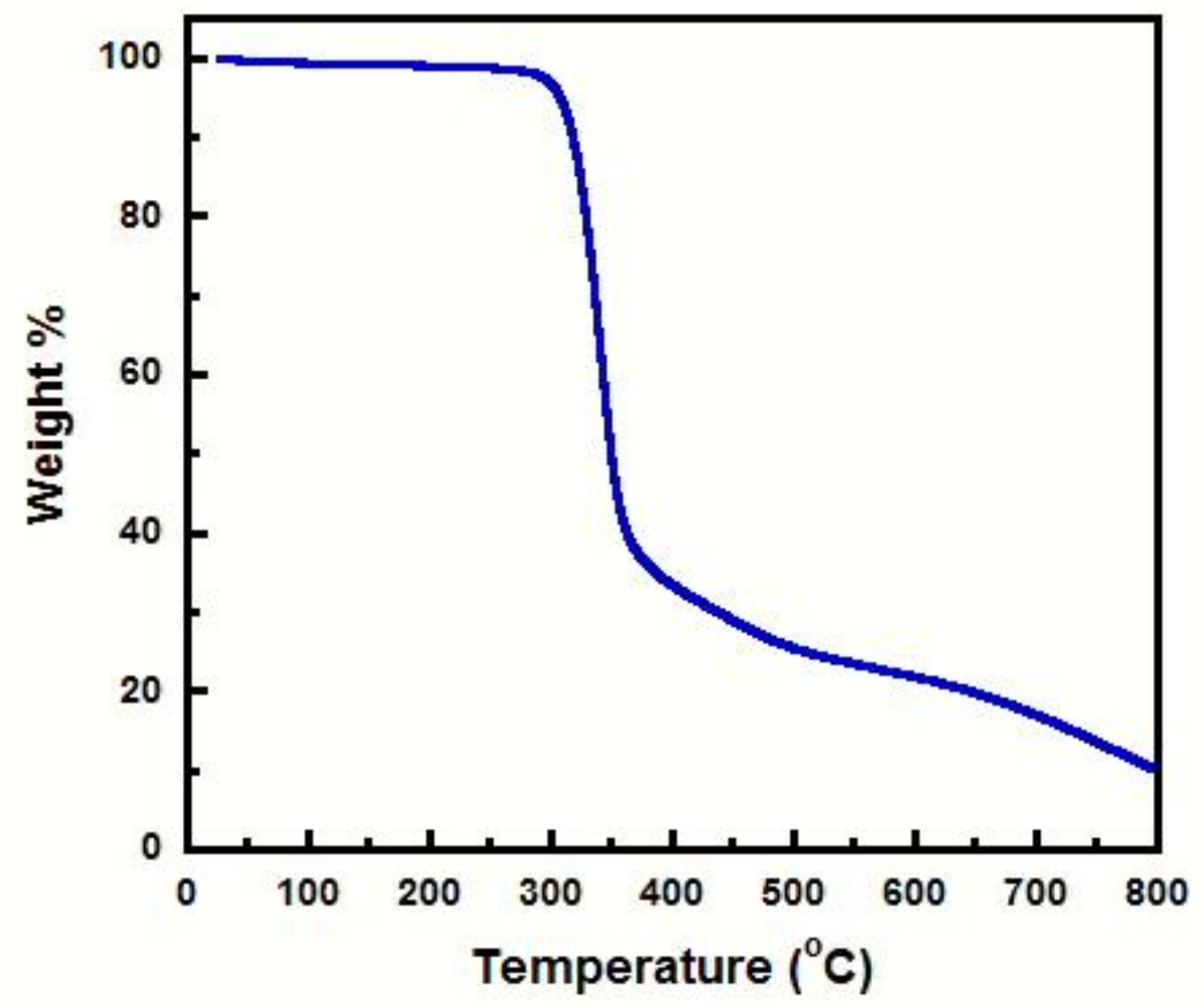

Figure S4. TGA thermogram of poly(methylidenelactide) (2). 


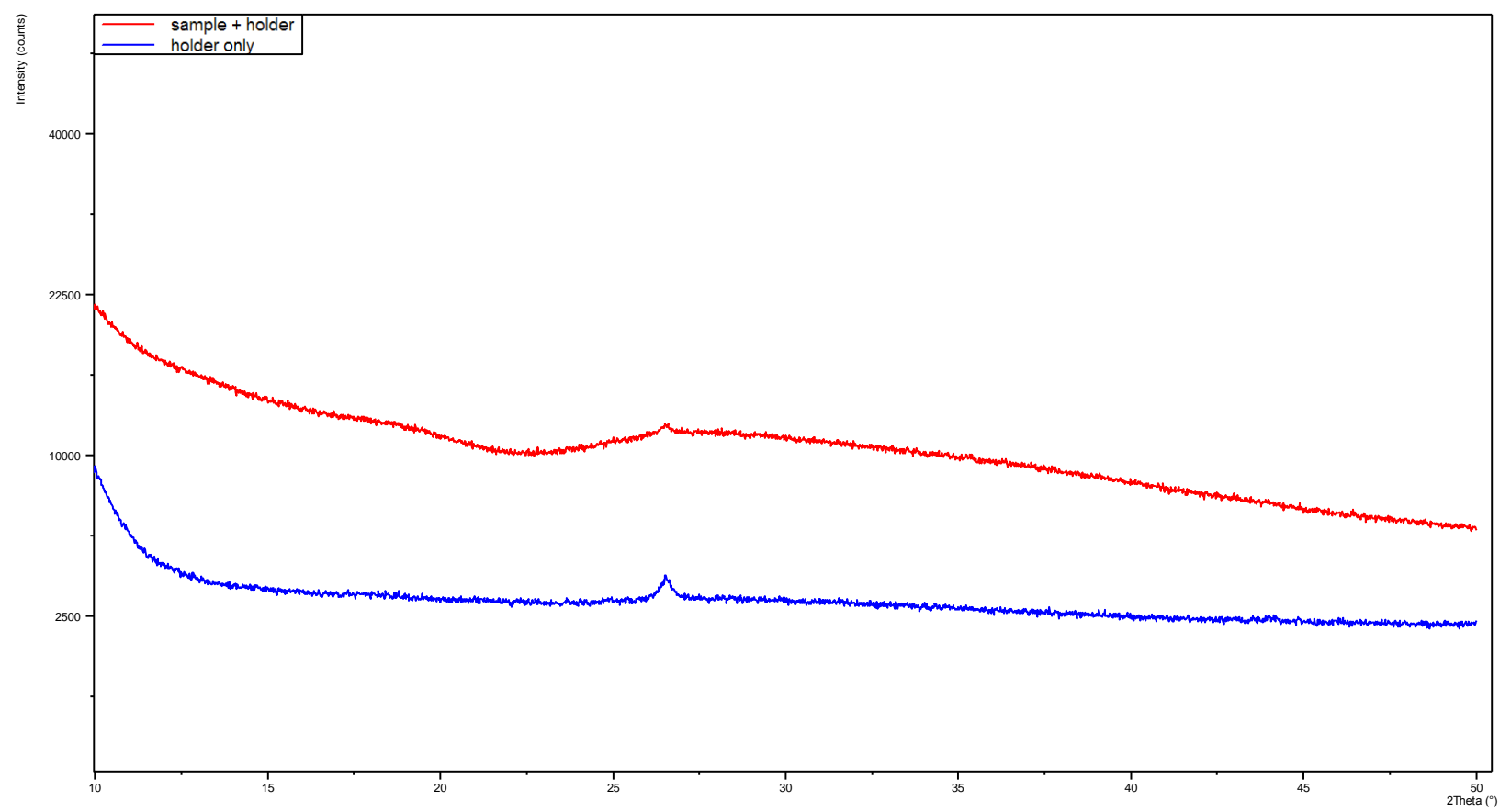

Figure S5. SAXS diffraction pattern of poly(methylidenelactide) (2), revealing no crystalline domains. 
Table S1. Hansen solubility parameters of methanol, tetrahydrofuran (THF) and blends therefrom, and relative solubility of 2 in each (co)solvent.

\begin{tabular}{|l|l|l|l|l|}
\hline & $\delta_{\mathrm{D}}\left(\mathrm{MPa}^{1 / 2}\right)$ & $\delta_{\mathrm{P}}\left(\mathrm{MPa}^{1 / 2}\right)$ & $\delta_{\mathrm{H}}\left(\mathrm{MPa}^{1 / 2}\right)$ & 2 solubility \\
\hline Methanol & 15.1 & 12.3 & 22.3 & None \\
\hline THF & 16.8 & 5.7 & 8.0 & Sparing \\
\hline $5: 1$ THF:Methanol (v:v) & 16.5 & 6.8 & 10.4 & Good \\
\hline $2: 1$ THF:Methanol $(\mathrm{v}: \mathrm{v})$ & 16.2 & 7.9 & 12.8 & High \\
\hline $1: 1$ THF:Methanol $(\mathrm{v}: \mathrm{v})$ & 16.0 & 9.0 & 15.2 & Good \\
\hline $1: 2$ THF:Methanol (v:v) & 15.7 & 10.1 & 17.5 & None \\
\hline $1: 5$ THF:Methanol (v:v) & 15.4 & 11.2 & 19.9 & None \\
\hline
\end{tabular}




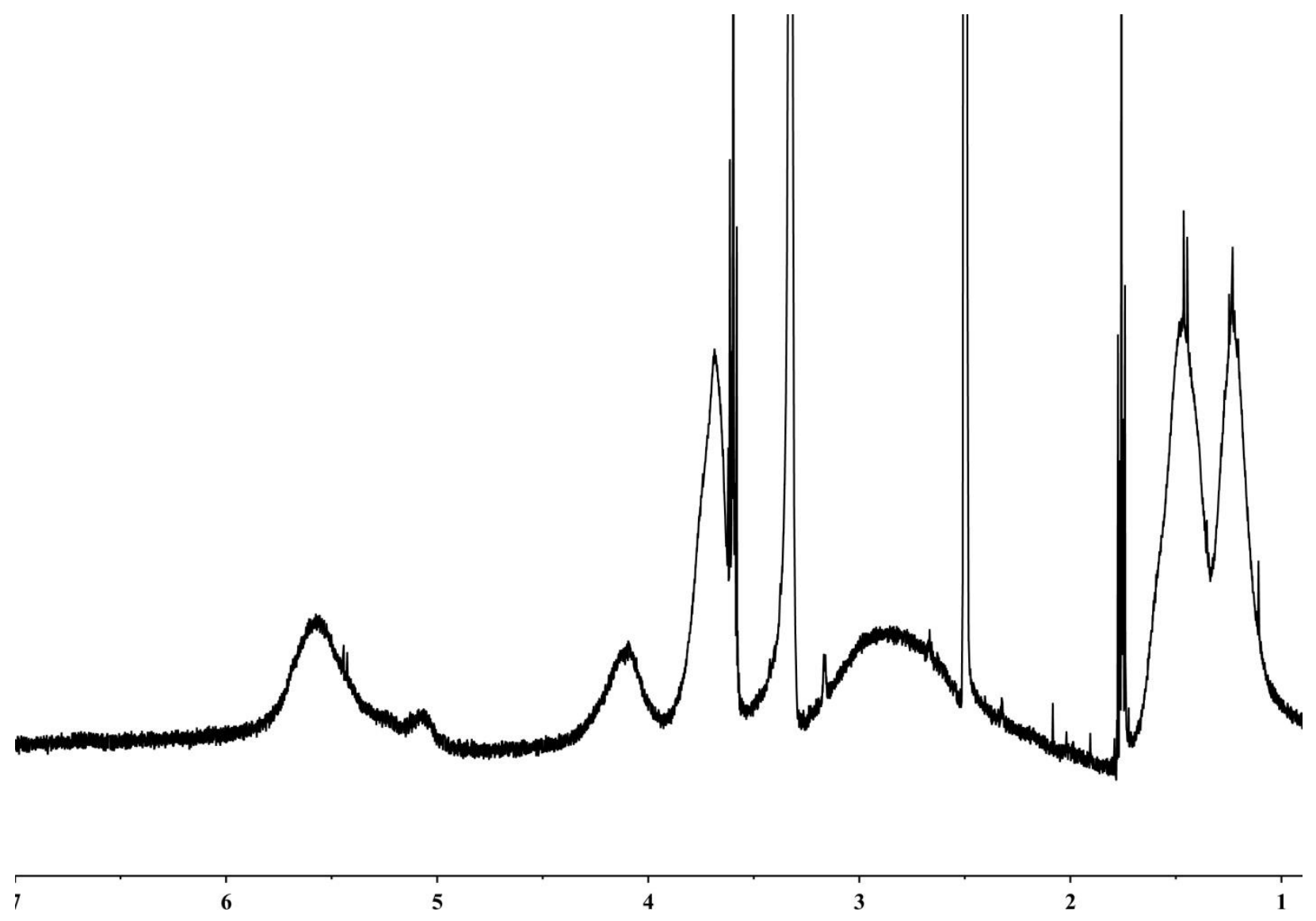

Figure S6. ${ }^{1} \mathrm{H}-\mathrm{NMR}$ spectra in d6-DMSO of 2 subject to transesterification conditions with methanol (1 wt. \% TBD, 300 equivalents methanol) at $-25^{\circ} \mathrm{C}$ after $24 \mathrm{~h}$. 

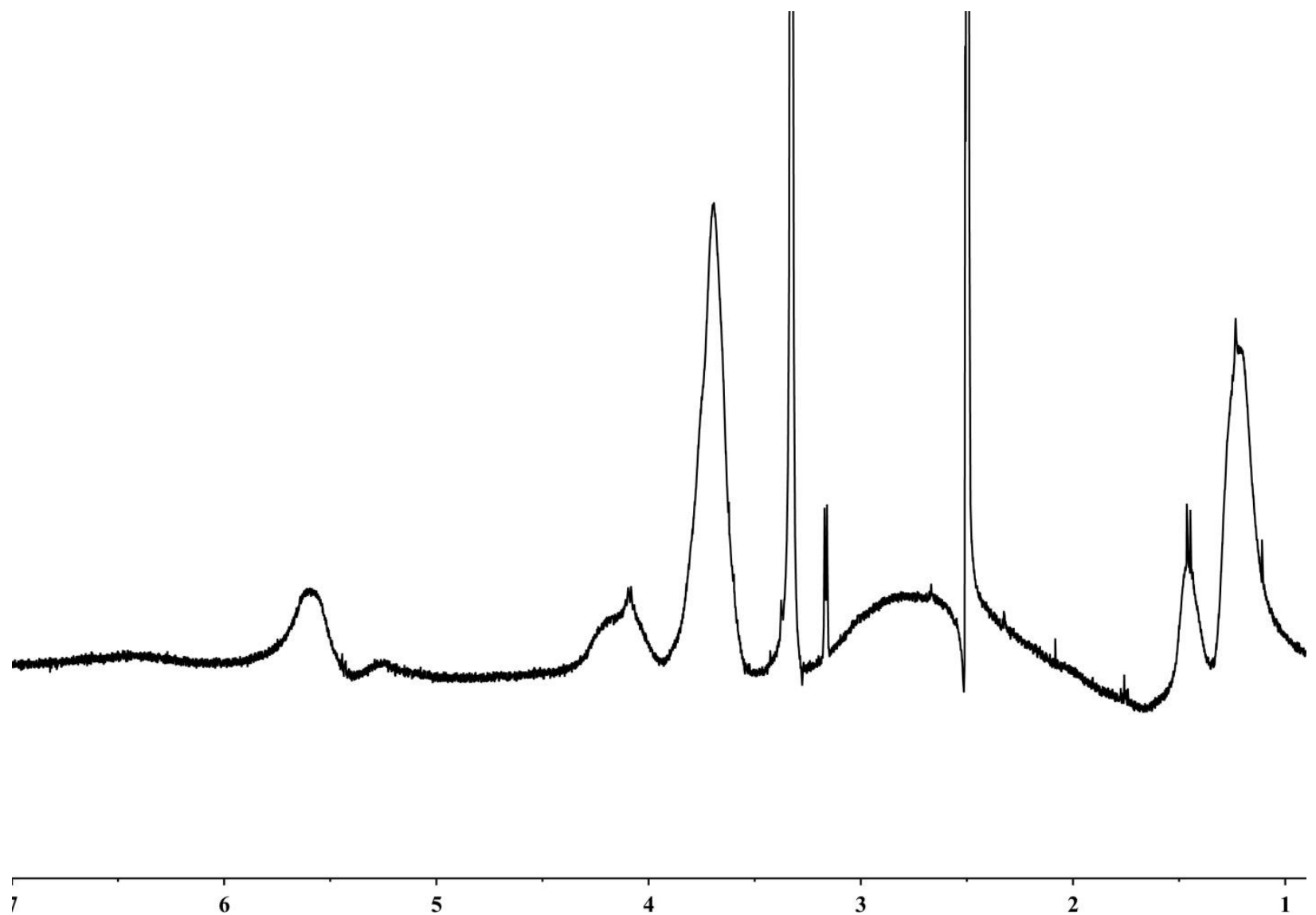

Figure S7. ${ }^{1} \mathrm{H}-\mathrm{NMR}$ spectra in d6-DMSO of 2 subject to transesterification conditions with methanol (1 wt. \% TBD, 300 equivalents methanol) at $5{ }^{\circ} \mathrm{C}$ after $24 \mathrm{~h}$. 


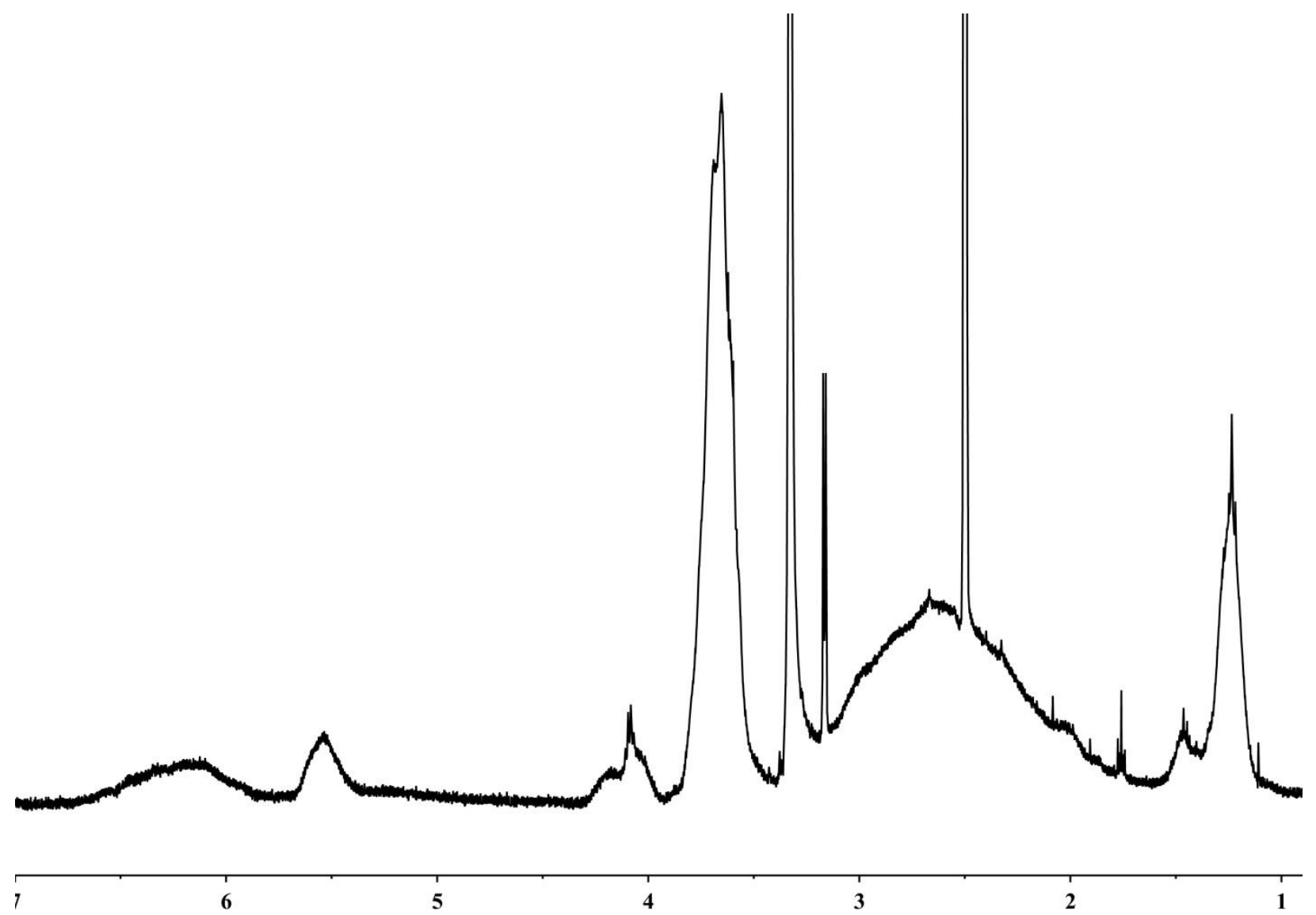

Figure S8. ${ }^{1} \mathrm{H}-\mathrm{NMR}$ spectra in d6-DMSO of 2 subject to transesterification conditions with methanol $(1 \mathrm{wt}$ \% $\%$ TBD, 300 equivalents methanol) at $23^{\circ} \mathrm{C}$ after $24 \mathrm{~h}$. 


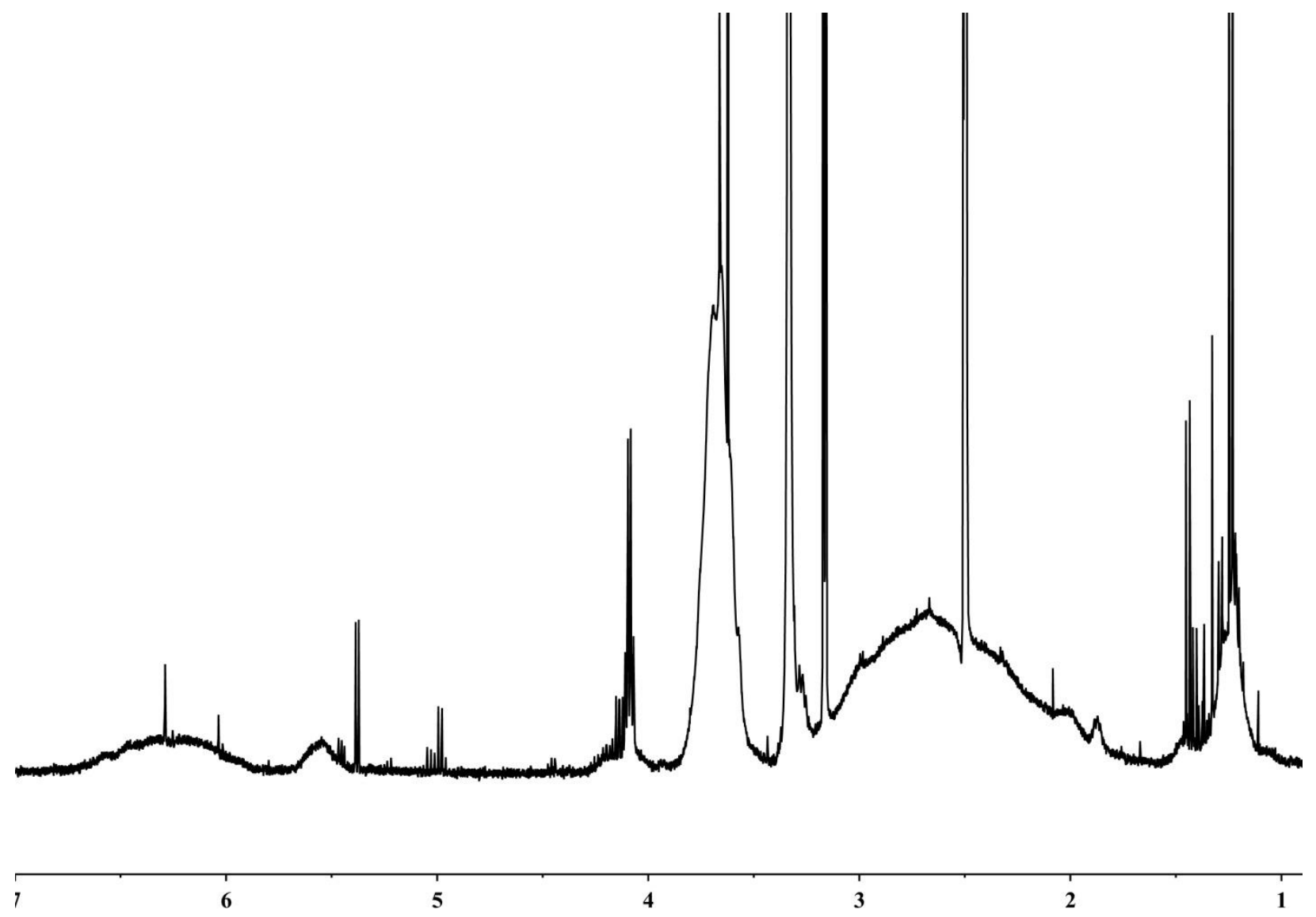

Figure S9. ${ }^{1} \mathrm{H}$-NMR spectra in d6-DMSO of 2 subject to transesterification conditions with methanol ( 1 wt. \% TBD, 300 equivalents methanol) at $60^{\circ} \mathrm{C}$ after $24 \mathrm{~h}$. 


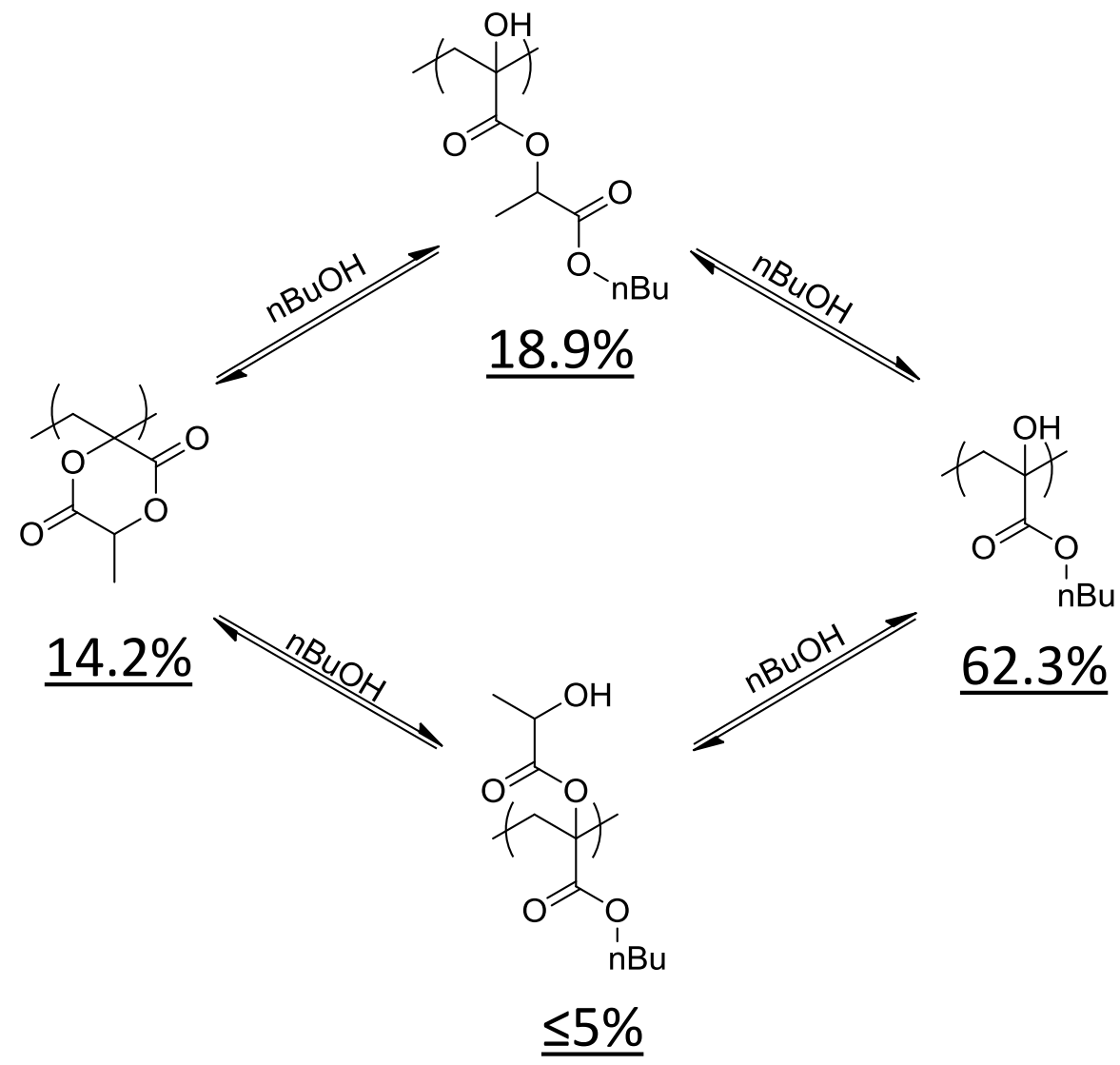

Figure S10. Equilibrium for the transesterification of 2 with n-butanol. The mole percentages of each structure at steadystate concentrations at $60^{\circ} \mathrm{C}$ are listed under the structures, determined by NMR. 


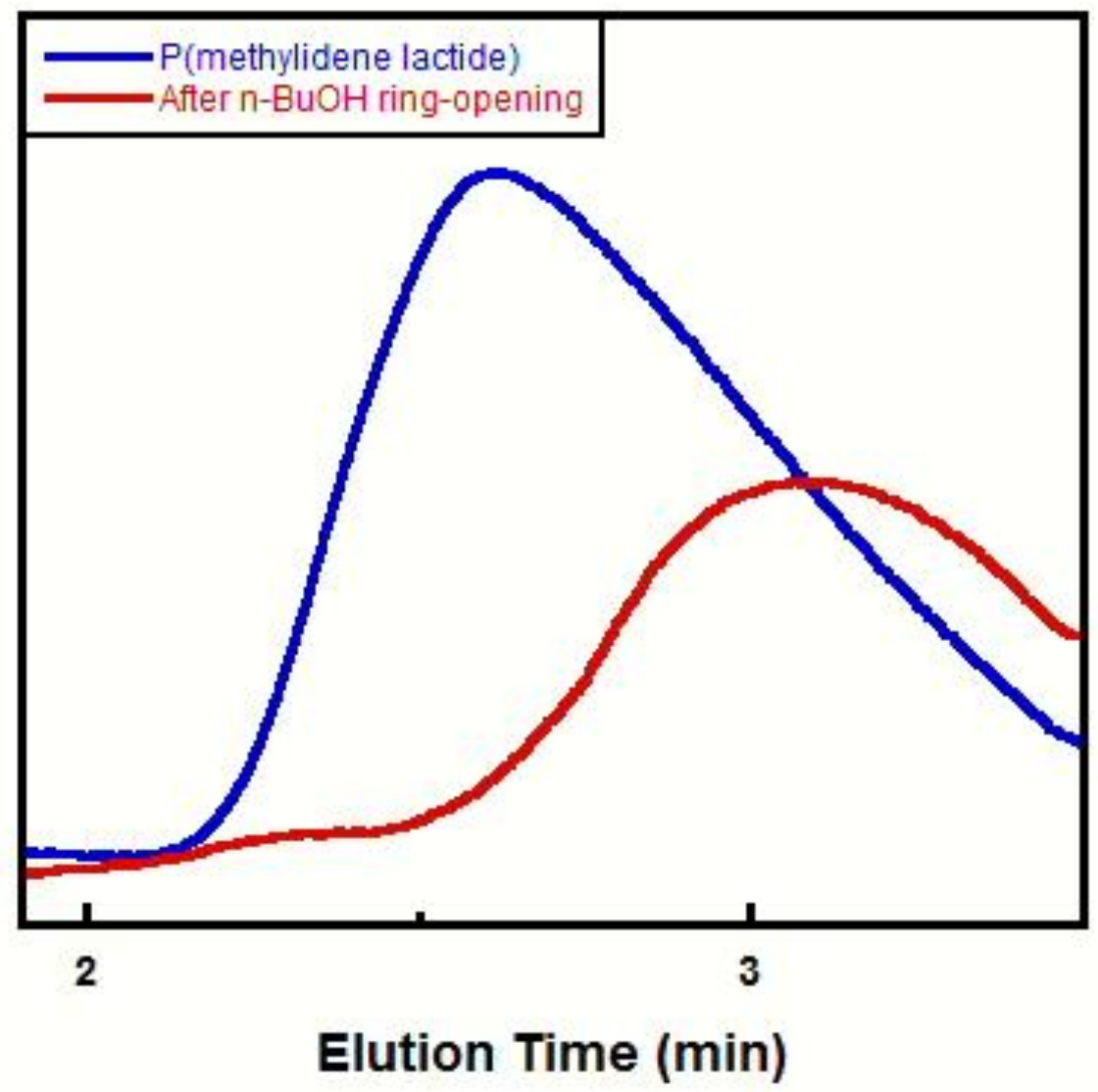

Figure S11. GPC chromatogram of poly(methylidenelactide) (2), and chromatogram of 2 after being subject to transesterification conditions in the presence of $n$-butanol ( 1 wt. \% TBD, 300 equivalents $n$-butanol)at $60{ }^{\circ} \mathrm{C}$. Neat 2: $M_{n}=$ $20.5 \mathrm{~kg} / \mathrm{mol}, \Theta=1.82 .2$ after transesterification with n-butanol: $M_{n}=15.3 \mathrm{~kg} / \mathrm{mol}, \Xi=1.74$. 


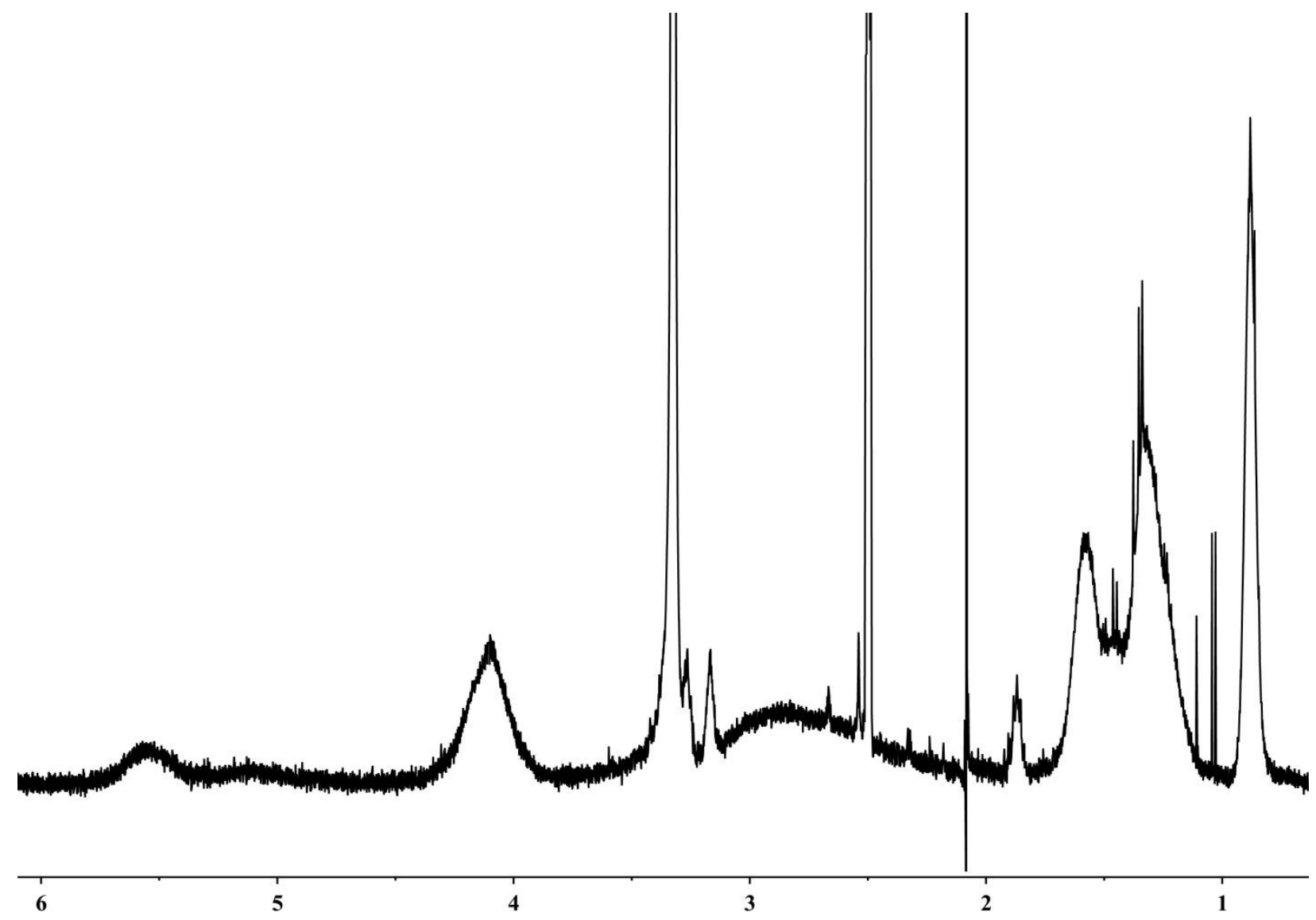

Figure S12. ${ }^{1} \mathrm{H}$-NMR spectra in d6-DMSO of 2 subject to transesterification conditions with $n$-butanol (1 wt. \% TBD, 300 equivalents $\mathrm{n}$-butanol) at $60^{\circ} \mathrm{C}$ after $24 \mathrm{~h}$. 


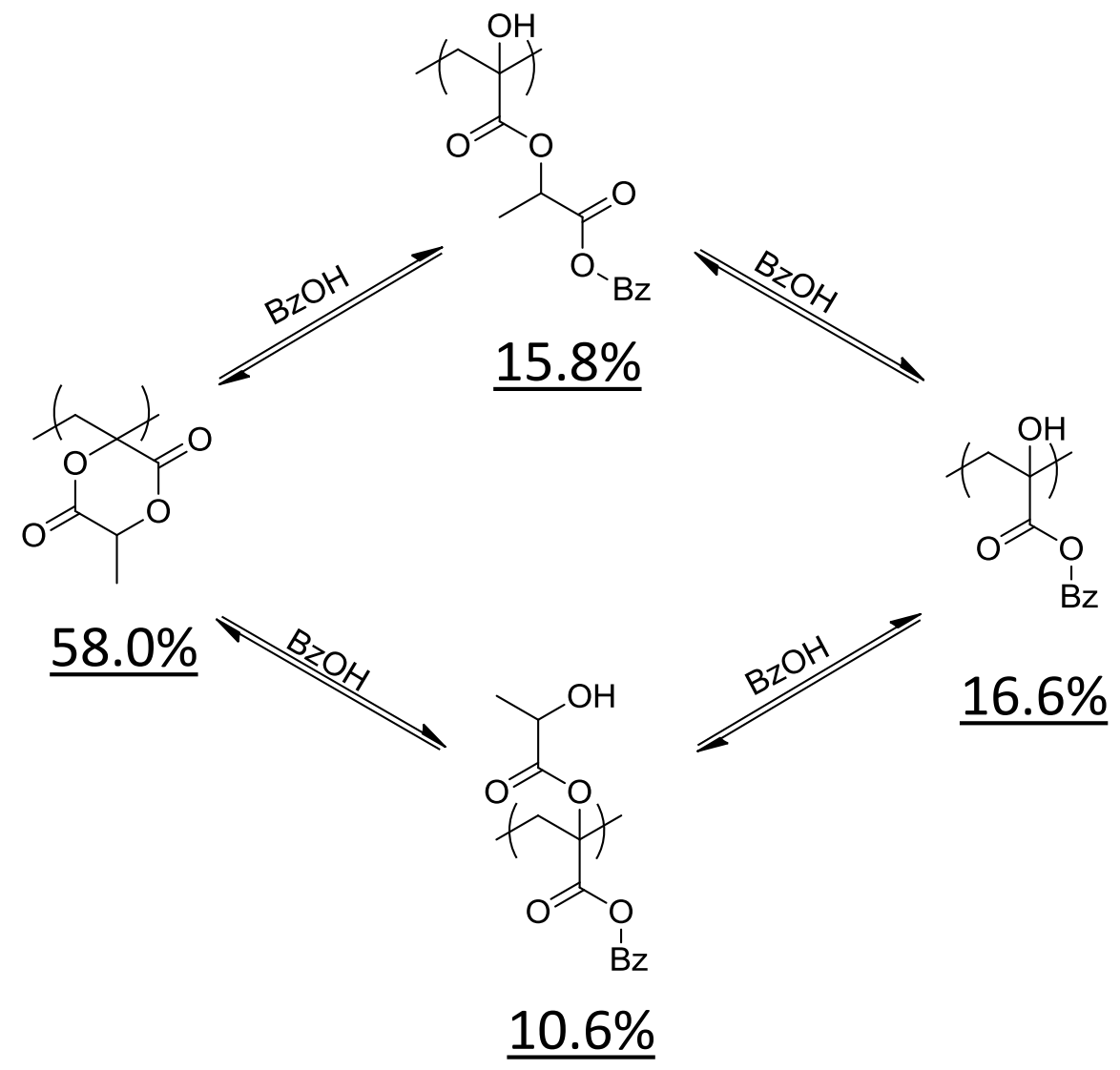

Figure S13. Equilibrium for the transesterification of $\mathbf{2}$ with benzyl alcohol. The mole percentages of each structure at steady-state concentrations at $60^{\circ} \mathrm{C}$ are listed under the structures, determined by NMR. 


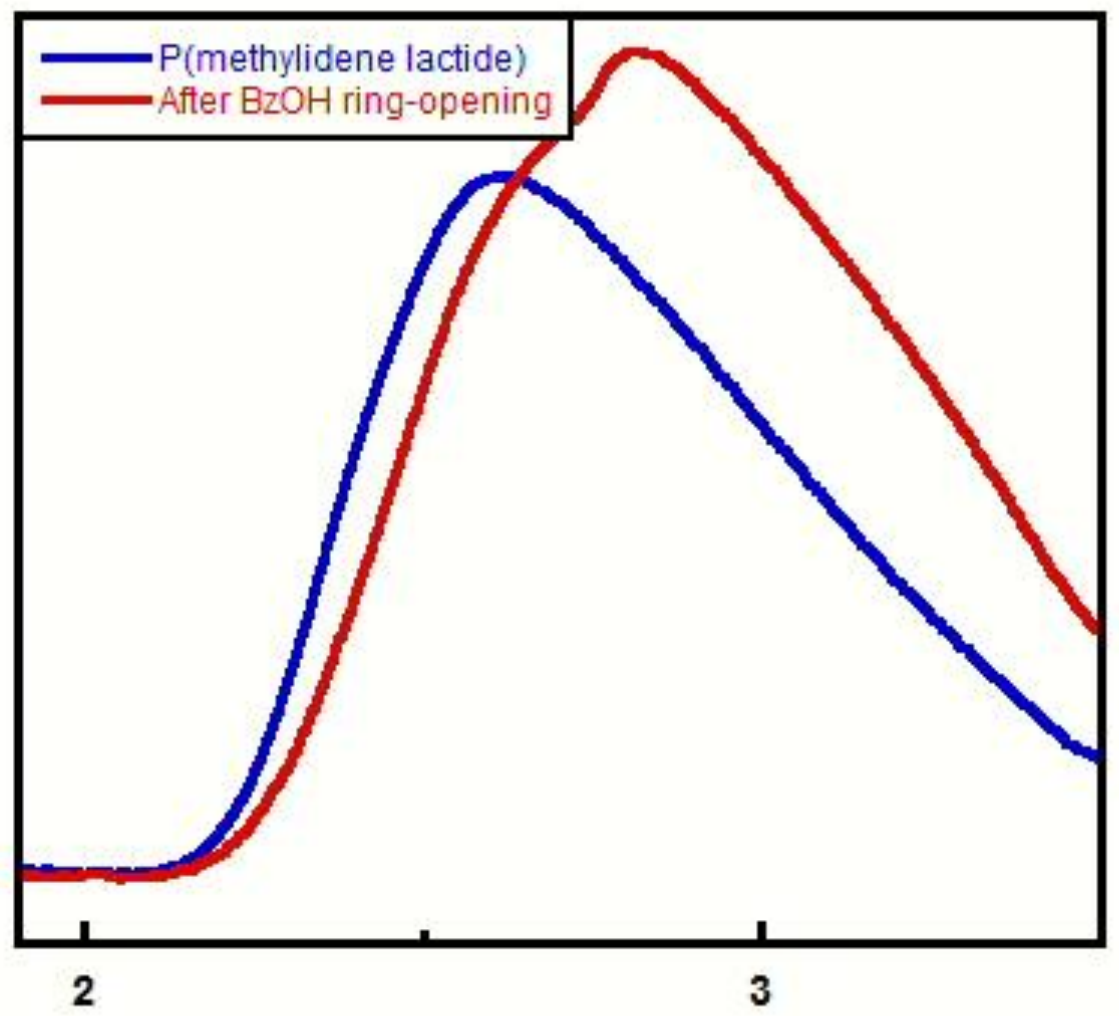

\section{Elution Time (min)}

Figure S14. GPC chromatogram of poly(methylidenelactide) (2), and chromatogram of 2 after being subject to transesterification conditions in the presence of benzyl alcohol (1 wt. \% TBD, 300 equivalents benzyl alcohol)at $60{ }^{\circ} \mathrm{C}$. Neat 2: $M_{n}=20.5 \mathrm{~kg} / \mathrm{mol}, \emptyset=1.82 .2$ after transesterification with benzyl alcohol: $M_{n}=18.7 \mathrm{~kg} / \mathrm{mol}, \emptyset=1.70$. 


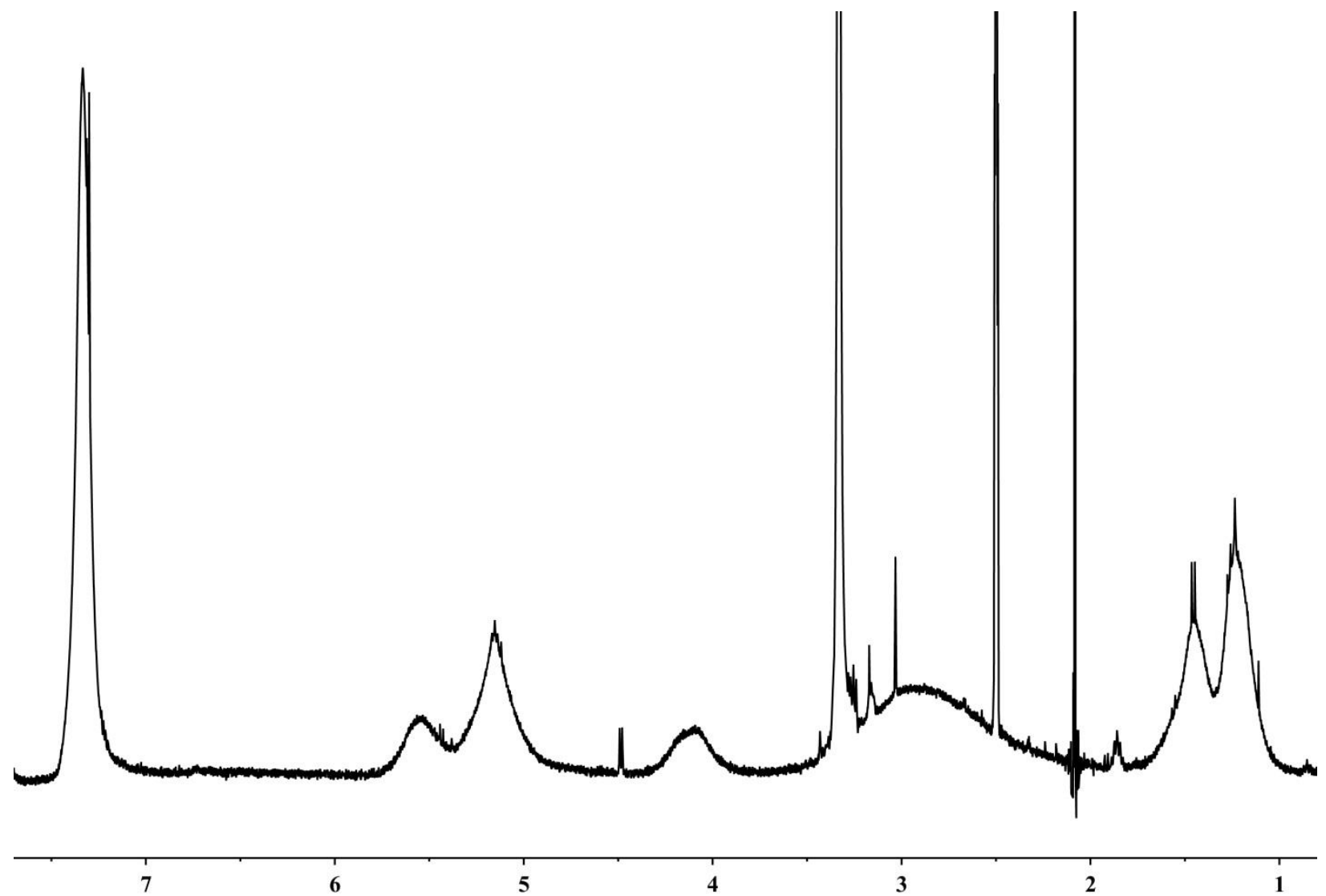

Figure S15. ${ }^{1} \mathrm{H}-\mathrm{NMR}$ spectra in d6-DMSO of 2 subject to transesterification conditions with benzyl alcohol (1 wt. \% TBD, 300 equivalents benzyl alcohol) at $60^{\circ} \mathrm{C}$ after $24 \mathrm{~h}$.

\section{References}

[1] Jing, F.; Hillmyer, M.A. J. Am. Chem. Soc., 2008, 130, 13826-13827. 